\title{
INSEMINACIÓN ARTIFICIAL Y FECUNDACIÓN IN VITRO HOMÓLOGAS POST MORTEM: LA FILIACIÓN Y LA SUCESIÓN SEGÚN LA LEY BRASILEÑA
}

\author{
Francieli PisetTa CECChInI \\ Especialista en Derecho Público por la FURB y la ESMESC; Brasil \\ Especialista en Derecho Procesal Civil por la LFG y la UNISUL, Brasil \\ Especialista en Derecho Civil por la FURB y la UNERJ, Brasil \\ pisetta@gmail.com
}

\section{INTRODUCCIÓN}

El hombre como animal político, en las palabras de Aristóteles ${ }^{1}$, necesita vivir en sociedad, y así surge la disciplina de Derecho para mantener la armonía entre los individuos. De este reglamento no se alejan dos hechos importantes de la naturaleza humana: la vida y la muerte. Existen reglas y principios relacionados con el propio nacimiento del hombre y sus consecuencias, las situaciones ocurridas en relaciones mantenidas en su vida, como la muerte, o, más específicamente, los efectos que acarrean para los sobrevivientes, entre otros aspectos.

A pesar de que la sociedad ha pasado por constantes mudanzas, algunas imperceptibles, otras considerables, polémicas o no, que acontecen mucho más rápidamente que el desarrollo del Derecho, nuevas situaciones surgen cada día, y muchas de ellas no se encuadran en disciplinas en el orden jurídico o, si lo hacen, son poco comunes, insuficientes para amparar una resolución satisfactoria. En este contexto se encuadran situaciones de filiación y de los derechos sucesorios de los hijos fecundados por inseminación artificial y fertilización in vitro homólogas post mortem.

La reproducción asistida, al contrario que en otros tiempos, es a día de hoy una realidad de nuestro día a día, habiendo innumerables técnicas ya consolidadas. Sus implicaciones, no obstante, acabaron por abalar estructuras que eran consideradas verdaderos dogmas del Derecho, como la determinación de la filiación y sus consecuencias, tales como el Derecho hereditario. Las dudas y problemáticas se agigantan cuando el momento

\footnotetext{
${ }^{1}$ M. Reale, Lições preliminares de Direito, 24. ${ }^{a}$ ed., São Paulo, Brasil, Saraiva, 1998, p. 31.
} 
de reproducción asistida es posterior a la abertura de la sucesión del hombre (post mortem), o sea, posterior a la muerte del marido o compañero, cuyo material genético y/o embrión formado con el mismo se encuentra criopreservado.

Por eso, este artículo busca analizar brevemente el tratamiento jurídico dado por la legislación brasileña para verificar la suficiencia o no de la disciplina del Código Civil de 2002, y alguna de sus problemáticas como, por ejemplo, si la regularización dada por el Código Civil brasileño de 2002 es o no suficiente para disciplinar las problemáticas referentes a la filiación y los derechos sucesorios de los hijos fecundados por inseminación artificial y fertilización in vitro post mortem. ¿Es admisible la realización de inseminación artificial o fertilización in vitro homólogas póstumas? ¿Existe presunción de filiación para los hijos fecundados en estas circunstancias? ¿Tienen los mismos derechos de herencia? ¿Los demás herederos de cujus deben esperar por plazo indeterminado para la realización de la repartición, ya que existe un hijo en potencial? ¿Dónde se sitúan los principios de la seguridad jurídica, de la intimidad del fallecido, de la no discriminación entre los hijos y la dignidad de la persona humana en contexto?

El debate es saludable porque es de eminente relevancia al saber jurídico, ya que es relevante para todo aplicador del Derecho, confundiéndose con la importancia social, pues también interesa a la sociedad como un todo y al Estado que debe asegurar su orden y paz en busca del bien común.

\section{REPRODUCCIÓN ASISTIDA}

\section{Conceptualización y técnicas de reproducción asistida}

La perpetuación da la especie es un principio de la naturaleza y se desenvuelve como un tipo específico de instinto en los animales. Los seres humanos, como animales racionales, pueden optar en determinado momento de su vida por tener o no su prole. Sin embargo, no todos consiguen hacer realidad este deseo por problemas de orden biológico, tales como la infertilidad que se considera enfermedad de acuerdo con la Clasificación Internacional de Enfermedades e su Décima Revisión (CID-10): enfermedades del aparato genitourinario (N00-N99), entre las cuales se constata la infertilidad masculina (N46) y la infertilidad femenina (N97) ${ }^{2}$.

\footnotetext{
2 Organização Mundial de Saúde, Classificação Internacional de Doenças: CID-10, s.f., disponible en www.cid10.hpg.ig.com.br.
} 
No obstante, la evolución biotecnológica ha posibilitado a los individuos con tales problemas la concretización de la voluntad de ser padres o madres por medios no naturales, independientes del acto sexual, que pueden ser llamados genéricamente de Reproducción Asistida (RA).

Según Genival França, la reproducción asistida es «o conjunto de procedimentos no sentido de contribuir na resolução dos problemas da infertilidade bumana, facilitando assim o processo de procriação quando outras terapêuticas ou condutas tenham sido ineficazes para a solução e obtenção da gravidez desejada» ${ }^{3}$.

De acuerdo con el primer artículo de la primera sesión de la Resolución núm. 1358/92 del Consejo Federal de Medicina: «As técnicas de Reprodução Assistida (RA) têm o papel de auxiliar na resolução dos problemas de infertilidade bumana, facilitando o processo de procriação quando outras terapêuticas tenham sido ineficazes ou ineficientes para a solução da situação atual de infertilidade» ${ }^{4}$.

De cualquier modo, la reproducción asistida utiliza técnicas específicas que materializa los avances biotecnológicos y de la ingeniera genética para superar la infertilidad humana.

Básicamente, las técnicas de reproducción asistida se agrupan en dos órdenes que varían con el local de la fecundación (dentro o fuera del organismo materno). Así, la fecundación puede darse: a) in vivo, esto es, en el propio cuerpo femenino; b) in vitro, o sea, fuera del organismo femenino, más específicamente en laboratorio ${ }^{5}$. Como ejemplos se citan la inseminación artificial y la fecundación in vitro, respectivamente.

Además de este criterio, las técnicas de reproducción asistida son clasificadas también de acuerdo con el origen de los gametos. Se observan dos modalidades: a) técnicas de reproducción asistida homologa (ocurre «entre gametas provenientes de um casal que assumirá a paternidade e a maternidade da criança» ${ }^{6}$, siendo que éste portará las informaciones gené-

${ }^{3}$ G. Veloso de França, Medicina legal, 6. ${ }^{a}$ ed., Rio de Janeiro, Guanabara Koogan, 2001, p. 225. Traducción: «El conjunto de procedimientos en el sentido de contribuir a la resolución de los problemas de infertilidad humana, facilitando así el proceso de procreación cuando otras terapias o conductas hayan sido ineficaces para la solución y abstención del embarazo deseado».

${ }^{4}$ Resolução núm. 1.358, de 11 de noviembre de 1992, CFM, $\mathbb{} 1$ (1992). Traducción: «Las técnicas de Reproducción Asistida (RA) tienen el papel de auxiliar en la resolución de los problemas de infertilidad humana, facilitando el proceso de procreación cuando otros tratamientos hayan sido ineficaces o ineficientes para la solución de la situación actual de infertilidad».

5 T. BRahe Fernandes, A reprodução assistida em face da bioética e do biodireito: Aspectos do Direito de família e do Direito das sucessões, Florianópolis, Diploma Legal, 2000, p. 54.

${ }^{6}$ A. Aldrovandi y D. GALvão DE FranÇA, «A reprodução humana assistida e as relações 
ticas de la pareja); b) técnicas de reproducción asistida heteróloga (ocurre cuando «são utilizados gametas de terceiros — tanto na doação de espermatozóides, quanto na doação de óvulos-, diante da impossibilidade do homem elou da mulher fornecerem seus próprios gametas» ${ }^{7}$ ).

Entre la variedad de técnicas de reproducción asistida desarrolladas por la ciencia médica se citan: a) inseminación artificial (IA o AI); $b$ ) fertilización in vitro (FIV o IVF); c) transferencia de gametos en las trompas de falopio (GIFT - Gamete Intra Fallopian Transfer ${ }^{8}$ ); d) transferencia peritoneal de gametos (POST - Peritoneal Oocyte Sperm Transfer ${ }^{9}$ ); e) transferencia de embriones en las trompas de falopio (ZIFT - Zygote Intra Fallopian Transfer ${ }^{10}$ ).

\section{Inseminación artificial y fertilización in vitro homólogas post mortem}

La inseminación artificial y la fertilización in vitro son las técnicas de reproducción asistidas más utilizadas. Tanto que son las más popularmente conocidas. Por eso este estudio se restringe a ellas.

La inseminación artificial (IA o AI) es una de las técnicas de reproducción humana médicamente asistida más difundida y aplicada en el mundo, especialmente en virtud del avance biotecnológico verificado que, a su vez, permite resultados más satisfactorios. A propósito, «na América Latina existe uma taxa global de gravidez de 27,8 por 100 por ciclo de tratamento de Fertilização In Vitro (FIV), de acordo com o Registro Latino-americano de $1998 \gg^{11}$.

Etimológicamente, la palabra inseminación deriva de la unión de semino y atus, que significa sembrar y plantar ${ }^{12}$. $\mathrm{O}$, según el origen latino, inse-

de parentesco», Revista Jurídica Consulex, 7, (2002), p. 35. Traducción: «Entre gametos provenientes de una pareja que asumirá la paternidad y la maternidad del niño».

7 G. Calmon Nogueira da Gama, A nova filiação: O biodireito e as relações parentais: $o$ estabelecimento da parentalidade-filiação e os efeitos jurídicos da reprodução assistida heteróloga, Rio de Janeiro, Renovar, 2003, p. 724. Traducción: «Son utilizados gametos de terceros - tanto en la donación de espermatozoides, cuanto en la donación de óvulos- ante la imposibilidad del hombre y/o de la mujer de proporcionar sus propios gametos».

8 Glossary of acronyms in reproductive medicine, «IV Voorburg», disponible en bttp:// www.ivf.nl/Acronyms_in_ART.htm.

${ }^{9}$ Glossary of acronyms..., op. cit.

${ }^{10}$ Ibid.

11 Red Latinoamericana de Reproducción Asistida, s.f., disponible en bttp://www. redlara.com/duvidas.asp\#8. Traducción: «En América Latina existe un porcentaje global de embarazo de 27,8 por 100 por ciclo de tratamiento de Fertilización In vitro (FIV) de acuerdo con el Registro Latinoamericano de 1998».

${ }_{12}$ T. L. Stedman, Dicionário médico, 27. ${ }^{\text {a }}$ ed., Rio de Janeiro, Guanabara Koogan, 2003, p. 805. 
minación surge de inseminare, de in (que significa dentro) y semen (que quiere decir semilla) ${ }^{13}$.

En la breve conceptualización de Elida Séguim: «A inseminação artificial consiste em uma injeção de sêmen, previamente colbido e selecionado, na cavidade uterina ou no canal cervical, no periodo em que o óvulo está maduro para fecundação» ${ }^{14}$.

Conforme al origen de los gametos, la inseminación artificial puede ser homóloga o heteróloga. Según Thomas L. Stedman, la inseminación artificial será homóloga cuando se da con el semen del marido y heteróloga cuando el semen sea de un donante que no es el marido del paciente $^{15}$. Obviamente, esto se debe extender también a unión estable, ya que es reconocida en Brasil como entidad familiar de acuerdo con el párrafo 3. ${ }^{\circ}$ del art. 226 de la Constitución Federal de $1988^{16}$.

Aquí en este estudio fue considerada la modalidad homóloga de inseminación artificial en que son utilizados los gametos de la pareja (marido y mujer, compañero y compañera) para la fecundación, o sea, no son aprovechadas las células germinativas de terceros donadores. Por consiguiente, el fruto de esta unión, el hijo generado, traerá consigo la carga genética de sus padres biológicos y afectivos, ya que éstos efectivamente asumirán el hijo.

También fue considerado en este estudio el momento post mortem de la inseminación artificial homóloga, que ocurre cuando se utilizan espermatozoides del fallecido marido o compañero. En este caso, los gametos fueron recogidos en vida para futuro y eventual aprovechamiento y, por tanto, debidamente conservados. Eso es posible gracias a la evolución científica en procesos de congelación.

La fecundación in vitro (FIV) o ectogenesis es una técnica «pioneira na reprodução assistida, simples e barata» ${ }^{17}$, reconocida mundialmente y responsable de la mayoría de los dieciséis mil bebés de probeta que nacen

${ }^{13}$ E. De OliveIra Leite, Procriações artificiais e o Direito: Aspectos médicos, religiosos, psicológicos, éticos e jurídicos, São Paulo, Revista dos Tribunais, 1995, p. 38.

14 E. SÉGuin, Biodireito, 3. ${ }^{a}$ ed., Rio de Janeiro, Lumen Juris, 2001, 90. Traducción: «La inseminación artificial consiste en una inyección de semen, previamente recolectado y seleccionado, en la cavidad uterina o en el canal cervical, en el periodo en que el óvulo este maduro para fecundación».

15 T. L. Stedman, Dicionário médico, op. cit., p. 805.

${ }_{16}$ Constituição dos Estados Unidos do Brasil, de 18 de septiembre de 1946, CFRB, 2014, $\$ 226$

17 A. Aldrovandi y D. Galvão de FranÇA, «A reprodução...», op. cit., p. 40. Traducción: «Pionera en la reproducción asistida, simple y barata». 
todos los años, siendo la más clásica de las modalidades de procreación médicamente asistida ${ }^{18}$.

Diferente de la inseminación artificial, aquí la fecundación es extracorpórea, o sea, ocurre en laboratorio fuera del organismo materno. Es lo que enseña Arnaldo Rizzardo al explayarse que por la fecundación in vitro «reúnem-se, extracorporalmente, num tubo de ensaio ou numa placa, o material genético masculino e o material genético feminino, o que leva à fecundação e à formação do ovo. Introduz-se o ovo no útero da mulher depois que inicia a divisão celular» ${ }^{19}$. Nilo Frantz enfatiza que esa técnica está compuesta de tres pasos fundamentales:

«O primeiro é a coleta dos gametas, que são os óvulos que a mulher produz; o segundo é a coleta dos espermatozóides do marido [ou companheiro], através de masturbação. Em seguida, retira-se a quantidade necessária de espermatozóides e faz-se com que esses dois gametas se unam [...]. Vinte e quatro horas depois, normalmente, tem-se o espermatozóide entrando no óvulo, e de 12 a 24 horas após ele expulsa metade de sua parte de cromossomas, ficando, então, o novo ser constituído, o ovo constituído. Esse conjunto se chama de ovo ou pré-embrião, «que vai se dividindo duas, quatro, oito, dezesseis e trinta e duas células, chamando isso de pré-embrião ou embrião. Quando atinge de cinco a seis dias, colocamos esses embriōes dentro do útero. Teremos aí a realização de uma fecundação in vitro, de um bebê de proveta» ${ }^{20}$.

También en esta técnica se dio el enfoque a la forma homóloga post mortem, en la cual es utilizado el embrión oriundo de la fecundación del

18 «Aplicação das novas tecnologias à reprodução humana: procriação medicamente assistida», Ciênciapt.net, s.f., disponible en bttp://www.cienciapt.net/dossiers/20040213/dossierPMA.pdf.

19 A. Rizzardo, Direito de família: Lei 10.406, de 10 de enero de 2002, Rio de Janeiro, Forense, 2002, p. 509. Traducción: «Se reúnen, extracorporalmente, en un tubo de ensayo o en una placa, el material genético masculino y el material genético femenino, lo que lleva a la fecundación y a la formación del huevo. Se introduce el huevo en el útero de la mujer después que inicia la división celular».

${ }^{20}$ N. FrantZ apud B. P. WeLteR, «Igualdade entre as filiações biológica e socioafetiva», Revista dos Tribunais, núm. 219 (2003). Traducción: «El primero es la colecta de los gametos, que son los óvulos que la mujer produce; el segundo es la colecta de los espermatozoides del marido [o compañero] a través de masturbación. En seguida se retira la cantidad necesaria de espermatozoides y se hace que se unan con esos dos gametos [...] Veinticuatro horas después, normalmente, se tiene el espermatozoide entrando en el óvulo, y de 12 a 24 horas después él expulsa la mitad de su parte de cromosomas, quedando, entonces, el nuevo ser constituido, el huevo constituido. Ese conjunto se llama de huevo o preembrión, "que se va dividiendo en dos, cuatro, ocho, dieciséis y treinta y dos células, llamandolo de preembrión o embrión. Cuando alcanza de cinco a seis días colocamos esos embriones dentro del útero. Tenemos ahí la realización de una fecundación in vitro, de un bebé de probeta”». 
óvulo de la esposa/compañera por espermatozoide de su fallecido marido/ compañero que es implantado en el interior del organismo de ella y no de una tercera mujer.

\section{LA FILIACIÓN EN LOS CASOS DE INSEMINACIÓN ARTIFICIAL Y FECUNDACIÓN IN VITRO HOMÓLOGAS POST MORTEM}

\section{Los criterios determinantes de la filiación}

Actualmente no se puede restringir la filiación como una relación de parentesco exclusivamente por lazos sanguíneos.

Aun en la consanguinidad existe una diferencia entre los hijos legítimos (que surgen de la relación matrimonial) e ilegítimos (que surgen de la relación extramatrimonial). En Brasil, la Constitución Federal de 1988 en su párrafo 6. ${ }^{\circ}$ del art. 227 terminó con esta discriminación, habiendolo corroborado la Ley núm. 8.069, de 13 de julio de 1990, más conocida como Estatuto del Niño y del Adolescente (art. 20), y el Código Civil de 2002 (art. 1.596).

Hoy, de hecho, es inadecuado concebir la filiación estrictamente por el criterio biológico y natural, pues el concepto de familia superó a los lazos sanguíneos para permitir también otras conexiones como la afectiva y la jurídica ${ }^{21}$.

En efecto, no se atribuye la paternidad y la maternidad solamente a aquel que generó el nuevo ser con su material genético, sino también a aquel que lo acompañó durante toda su vida, criándolo afectivamente y dedicándole amor. En el mismo sentido, el advenimiento de las técnicas de reproducción asistida tiene nítidamente mitigada la verdad biológica.

Silvio de Salvo Venosa define la filiación y presenta algunas consecuencias jurídicas:

«Sob o aspecto do Direito, a filiação é um fato jurídico do qual decorrem inumeros efeitos. Sob perspectiva ampla, a filiação compreende todas as relações, e respectivamente sua constituição, modificação e extinção, que têm como sujeitos os pais com relação aos filhos. Portanto, sob esse prisma, o direito de filiação abrange também o pátrio poder, atualmente denominado

${ }^{21}$ G. Calmon Nogueira da Gama, A nova filiação..., op. cit., p. 467. 
poder familiar, que os pais exercem em relação aos filhos menores, bem como os direitos protetivos e assistenciais em geral [...]. A filiação é, destarte, um estado, o status familiae [...]. O termo filiação exprime a relação entre o filho e seus pais, aqueles que o geraram ou o adotaram» ${ }^{22}$.

Esta vez, contra la amplitud actual que se investiga, se entiende apropiado que tanto la paternidad como la maternidad sean comprendidos como la relación de parentesco existente entre los hijos y, respectivamente, el padre y la madre.

Guilherme Calmon Nogueira da Gama clasifica las especies de filiación $^{23}$ en: a) filiación matrimonial y extramatrimonial (utiliza como modelo el casamiento: hijos generados en el casamiento o fuera de él, lo que hoy fue abolido como mencionamos anteriormente); b) filiación resultante de procreación carnal y de procreación asistida (utiliza como criterio la relación sexual, habiendo fecundación con o sin relación sexual); c) filiación natural y civil (consanguinidad u otro origen) ${ }^{24}$; d) filiación legal (jurídica), biológica e afectiva ( la primera depende del criterio elegido en el orden jurídico, como es el casamiento aliado a la paternidad; la segunda se basa en el reconocimiento jurídico de que el hecho natural es fuente inmediata del vinculo jurídico de filiación, como es el caso de la relación sexual; la tercera, que antes alcanzaba solamente la adopción, adquirió mayor extensión en la medida en que se trata del vínculo oriundo de la relación socio afectiva constatada entre hijo y padres o entre hijos y apenas uno de ellos, teniendo como fundamento el afecto, el sentimiento existente entre ellos).

Los hijos generados por inseminación artificial o fertilización in vitro homólogas se ajustan en la filiación resultante de la procreación asistida

22 S. De Salvo Venosa, Direito civil: Direito de família, 4. a ed., São Paulo, Atlas, 2004, pp. 275-276. Traducción: «Bajo el aspecto del Derecho, la filiación es un hecho jurídico del cual transcurren inúmerables efectos. Bajo una perspectiva amplia, la filiación comprende todas las relaciones, y respectivamente su constitución, modificación y extinción, que tiene como sujetos los padres en relación a los hijos. Por tanto, bajo este punto de vista el derecho de filiación alcanza también la patria potestad, actualmente denominado poder familiar, que los padres ejercen en relación a los hijos menores, bien como los derechos de protección y asistenciales en general [...] La filiación es, así, un estado o status familiae [...]. El término filiación exprime la relación entre el hijo y sus padres, aquellos que lo generaron o adoptaron». 480-481.

${ }_{23}$ G. Calmon Nogueira da Gama, A nova filiação..., op. cit., pp. 467, 471, 476 y

${ }^{24}$ El Código Civil Brasileño de 2002 tiene en su art. 1.593: «O parentesco é natural ou civil, conforme resulte de consangüinidade ou outra origem». Traducción: «El parentesco es natural o civil, según el resultado de la consanguinidad o de otra fuente». 
y en la filiación natural, ya que los gametos utilizados en la fecundación son de la pareja que asumirá la paternidad del hijo generado, existiendo, por tanto, lazos sanguíneos, lo que no ocurre en la modalidad heteróloga - ya que los gametos femeninos y/o masculinos pueden proceder de tercero(s) donante(es)—.

\section{Disciplina legal dada en Brasil acerca de la filiación: poblemáticas y reflexiones especificas en los casos de inseminación artificial y fertilización in vitro homólogas post mortem}

Como ya mencionamos, la inseminación artificial y la fertilización in vitro homologadas se dan mediante la utilización de células germinativas del hombre y de la mujer que ejercerán la paternidad del hijo generado. Obviamente, por tanto, hay identidad genética entre los padres y el generado, razón por la cual no existen problemas en la determinación de la filiación.

Sin embargo, lo mismo no se puede afirmar cuando la inseminación artificial o la fertilización in vitro homólogas se verifican en momento póstumo, o sea, después del óbito del padre, una vez que algunos aspectos no encuentran resolución en la ley.

El Código Civil brasileño de 2002 mantuvo las presunciones de filiación existentes en el Código Civil de 1916, ampliando el rol:

«Art. 1.597. Presumem-se concebidos na constância do casamento os filhos:

i) nascidos cento e oitenta dias, pelo menos, depois de estabelecida a convivência conjugal;

ii) nascidos nos trezentos dias subseqüentes à dissolução da sociedade conjugal, por morte, separação judicial, nulidade e anulação do casamento;

iii) havidos por fecundação artificial homóloga, mesmo que falecido o marido;

iv) havidos, a qualquer tempo, quando se tratar de embriões excedentários, decorrentes de concepção artificial bomóloga;

v) havidos por inseminação artificial heteróloga, desde que tenha prévia autorização do marido» 25 .

25 S. De Salvo Venosa (org.), Novo Código Civil: Texto comparado: Código Civil de 2002, Código Civil de 1916, São Paulo, Atlas, 2002, pp. 412-413. Traducción: «Art. 1.597. Se presumen concebidos en la constancia del casamiento los hijos: $i$ ) nacidos ciento ochenta días, por lo menos, después de establecida la convivencia conyugal; ii) nacidos en los 
Ocurre que el nuevo Código presentó algunas fallas, pues el abordaje fue incompleto. Se observa, por ejemplo, que hubo una restricción del tipo de vínculo entre la pareja, ya que se limitó al casamiento, no revelando soluciones para la inseminación ocurrida entre personas que viven en unión estable. No existe presunción de filiación en la modalidad familiar de unión estable, dejando de avanzar la legislación en este sentido.

Otro aspecto es en relación al inciso II del artículo citado. La primera equivocación es la terminología «fecundación artificial», pues toda fecundación es natural, siendo artificial solamente la técnica. Visto esto, a primera vista parece que el legislador pretendió destacar la presunción de filiación, cuando ha fallecido el marido, sólo para el hijo que surge de fertilización in vitro homóloga, ignorando todas las otras formas existentes de reproducción médicamente asistida. El problema surge cuando se habla de fertilización in vitro en la que la fecundación ocurre fuera del cuerpo materno, siendo que los embriones pueden permanecer criopreservados por mucho tiempo; entonces se entraría en la eterna discusión acerca del exacto momento del origen de la vida, de cuándo el ser humano es considerado como tal para efectos jurídicos. Si no bastase, el inciso III no establece un plazo para la «fecundación artificial» homologa ocurrida después de la muerte del hombre, al igual que no exige la previa autorización de éste en el caso de eventual ocurrencia.

Otra ponderación pertinente es la terminología y la limitación restricta contenida en el inciso IV del citado dispositivo legal. Nuevamente se utilizó el término «concepción artificial» cuando, en verdad, toda la concepción es natural. Sin embargo, se comprende que la referida expresión quiere decir respecto a cualquier modalidad de reproducción asistida. La limitación restricta, a su vez, es en relación a los embriones excedentarios, pues no se consideró la hipótesis de que el material genético, a pesar de ser previamente recogido, no habría sido todavía transformado en embriones o, simplemente, que no sería caso de embrión excedente. En esta ultima suposición, sin embargo, se entiende aplicable el principio de que «quien puede más puede menos», de modo que, si la presunta filiación para el embrión excedentario, lo mismo debe ocurrir con el no excedentario.

trescientos días subsecuentes a la disolución de la sociedad conyugal por muerte, separación judicial, nulidad y anulación del casamiento; iii) generados por fecundación artificial homóloga, de la misma manera que fallecido el marido; iv) generados en cualquier tiempo, cuando se trata de embriones excedentarios, resultantes de concepción artificial homóloga; v) generados por inseminación artificial heteróloga desde que tenga autorización previa del marido». 
Otra anotación es relacionada al inciso V, en el cual se verifica la presunción de filiación de aquellos generados solamente por inseminación artificial heterólogica y con previa autorización del marido. Nuevamente existe una limitación de la gama de técnicas de reproducción asistida, descartándose todas, salvo la de inseminación artificial.

Delante de estas observaciones críticas se yergue con mayor elevación la indagación acerca del tratamiento que debe ser dado, específicamente, en los casos de inseminación artificial y fertilización in vitro homóloga post mortem, siendo didácticamente conveniente la separación considerando el casamiento y la unión estable.

En la hipótesis de la reproducción asistida si ocurre de la forma homóloga y póstuma, existiendo casamiento, se cuestiona la posibilidad, inclusive, de la aplicación del inciso II del art. 1.597 (se presume concebidos en constancia de casamiento los hijos nacidos a los trescientos días subsecuentes a la disolución de la sociedad conyugal por muerte, separación judicial, nulidad e anulación del casamiento).

Aunque consten expresamente las técnicas de reproducción asistida en otros incisos del indicado artículo, se entiende que tal circunstancia, al principio, no frustraría la utilización del inciso II, tanto en la inseminación artificial como en la fertilización in vitro homólogas post mortem, ya que es completamente posible que, luego después de la muerte del hombre, sea efectuada la reproducción médicamente asistida. Se observa que el plazo de trescientos (300) días es suficiente para que ocurra una gestación.

Tomándose en consideración aun la interpretación conjunta del inciso II con el caput del art. 1.597 se llega a otro punto crítico. Se observa que el caput revela la presunción de la paternidad apenas en la constancia del casamiento. Luego el hijo nacido en los trescientos (300) días siguientes a la disolución conyugal es presumiblemente concebido durante el casamiento. Ocurre que, conforme a lo ya planteado, el hijo puede ser concebido y nacido después de la disolución conyugal, que sería el caso de la inseminación artificial y de fertilización in vitro homólogas post mortem. En esta hipótesis ¿también existiría la presunción de que la concepción ocurrió durante el matrimonio?

Ante tal cuestionamiento entra en contradicción la disposición legal, una vez que la muerte es una de las causas de disolución de la sociedad conyu$\mathrm{gal}^{26}$. Siendo así, si con la muerte no existe más casamiento —-mucho menos

${ }^{26}$ «Art. 1.571. A sociedade conjugal termina: I -pela morte de um dos cônjuges». Vid. 
constancia- en el momento de la concepción, no debe de reflexionar de la presunción de la filiación. En este caso, se debe buscar encuadramiento en los otros incisos del art. 1.597.

El inciso III del citado art. 1.597 es específico sobre a la fecundación artificial homóloga póstuma (se presumen concebidos en la constancia del casamiento los hijos generados por fecundación artificial homóloga, de la misma forma que fallecido el marido).

Paulo Luiz Neto Lôbo enfatiza que persiste la presunción de paternidad del fallecido en el caso de la fecundación artificial homóloga ocurrir después del plazo de trescientos (300), mas condiciona esta presunción la prueba de que el gameto, utilizado por la entidad que se incumbió en el almacenamiento, es de cujus y de que hay previo y expreso consentimiento de esto ${ }^{27}$. Este consentimiento previo y expreso estaría de acuerdo con el principio de intimidad con el fallecido, sin embargo, no es exigido en el inciso III del art. 1.597. Pero he aquí más una deficiencia legislativa que podría evitar el uso indebido de la práctica de reproducción asistida homóloga póstuma. De otro punto de vista, suprimir la presunción de filiación en virtud de la falta de concordancia previa y expresa del padre — cuando no exigida legalmente- estaría siendo un daño para el hijo generado.

Siendo así, se evidencia un conflicto entre la eventual desventaja enfrentada por el hijo y la existencia de eventuales problemas — como, por ejemplo, la necesidad del de cujus manifestar previamente su consentimiento para evitar cuestiones de sucesión que envuelven a hijos generados y demás herederos- que podrían ser ocasionados con la práctica de reproducción asistida homóloga post mortem.

En esta oportunidad conviene destacar que, en el área médica, existe el denominado término del consentimiento informado. En el caso de la utilización de técnicas de reproducción asistida, el ítem tres de la sección de los principios generales de la Resolución núm. 1.358/92 del Consejo Federal de Medicina obliga a la formulación de un documento de consentimiento informado, en formulario especial y completo con la concordancia, por escrito del paciente o de la pareja infértil ${ }^{28}$. Aun que este término

S. De Salvo Venosa (org.), Novo Código Civil..., op. cit., p. 406. Traducción: «Art. 1.571. La sociedad conyugal termina: i) la muerte de un cónyuge».

${ }^{27}$ P. L. NetTo LôBo, «Direito de família, relações de parentesco, direito patrimonial: arts. 1.591 a 1.693», en A. VillaçA AzEvedo (coord.), Código Civil comentado, São Paulo, Atlas, 2003, p. 50.

${ }^{28}$ Resolução núm. 1.358, de 11 de noviembre de 1992. 
se refiere a la práctica de la reproducción asistida y no a las problemáticas debatidas en esta pesquisa referente a filiación y a los derechos de sucesión de los hijos generados por inseminación artificial o fertilización in vitro homólogas póstumas.

Cuando el inciso IV del art. 1.597 (se presume concebidos en la constancia del casamiento los hijos generados, a cualquier tiempo, cuando se trata de embriones excedentarios, que surgen de concepción artificial homóloga), a pesar de no prever el momento post mortem, la aplicabilidad es posible justamente delante de la expresión «a cualquier tiempo», esto porque no existe definición legal de la oportunidad temporal de concepción, se antes o después de la muerte del hombre que tuvo colectados sus gametos. Luego, plenamente posible adaptar el inciso tratado a los casos de reproducción asistida homóloga que sean post mortem.

Para Tycho Brahe Fernandes, se hace necesario el previo consentimiento del hombre para que la filiación sea establecida: «No caso do falecimento de homem casado ou que esteja vivendo em união estável, que previamente consentiu na utilização de seu material genético após a sua morte, sua paternidade restará estabelecida quando do nascimento». ${ }^{29}$ Sin embargo, aquí también la ley exige este previo y expreso consentimiento, lo que sería importante porque, más allá del hombre estar consciente que podrá ser padre después de su muerte, sería una seguridad para el propio hijo generado en lo que condiciona a la definición de paternidad correspondiente sin necesidad de investigaciones posteriores.

Va más allá de la cuestión temporal. Al final ¿qué seguridad jurídica existe con la posibilidad de la realización de la reproducción asistida homóloga post mortem en cualquier momento? ¿Los familiares del fallecido deben permanecer presos a la posibilidad de una futura utilización de material recolectado en reproducción asistida en los moldes ahora comentados ad eternum? Se tratan de preguntas sin respuestas, pues el Código Civil Brasileño de 2002 nada disciplinó en estos aspectos, permaneciendo la norma abierta.

Estos cuestionamientos fueron solucionados por España, con la finalidad de permitir la reproducción asistida homóloga post mortem, adoptándose dos criterios, siendo el consentimiento previo y expreso del hombre y un límite de tiempo definido: «... o modelo espanhol [...] permite a insemi-

29 T. Brahe Fernandes, A reprodução assistida..., op. cit., p. 117. Traducción: «En el caso de fallecimiento del hombre casado o que esté viviendo en unión estable, que previamente consintió en la utilización de su material genético después de su muerte, su paternidad permanecerá establecida en el nacimiento». 
nação posterior a [sic] morte do doador, desde que feita dentro do prazo de 6 meses a contar do falecimento do mesmo e se consentida em escritura pública, resguardando à criança todos os direitos advindos da filiação» ${ }^{30}$.

Si no bastase la cuestión temporal, el Consejo Federal de Medicina a través de la Resolución núm. 1.358/92, revela la existencia de una fase anterior a la embrionaria o sea, de pre-embriones ${ }^{31}$. A la presunción de filiación no podría ser aplicada mediante el inciso en estudio si analizada literalmente la ley, ya que la disposición es expresa en relación a «embriones excedentarios», no tratándose de «pre-embriones». Sin embargo, se comprende, se trata de más una equivocación del legislador brasileño, o sea, también debe ser considerado en el inciso en aprecio los niveles anteriores al embrionario, bajo la pena de incurrir en violación al principio de igualdad.

Sin embargo, ¿de qué forma aplicar el principio de igualdad delante de la tormentosa discusión acerca del inicio de la vida del ser humano? El debate acerca del momento del origen del ser humano no constituye objeto de esta pesquisa, no obstante vale determinar que igualmente no existe posicionamiento pacifico en relación al momento del embrión ser considerado como tal. En esta dirección, para Heloisa Helena Barbosa, «Não [...] parece razoável considerar-se o embrião antes da transferência para o útero materno um nascituro» ${ }^{32}$. Siguiendo la misma línea de raciocinio, existe que «O Projeto de Lei $n^{\circ}$ 90, de 1990, do Senado Federal, que dispõe sobre a reprodução assistida, estabelece que não se aplicam aos embriões originados in vitro, antes da introdução no aparelho reprodutor da mulher receptora, os direitos assegurados ao nascituro ${ }^{33}$. Estos entendimientos, aun discriminan al feto que está en el vientre materno de aquel que está crio preservado en laboratorio.

30 S. Barbas apud F. Alves Ferreira, «Vivendo sem respirar, morrendo sem chance de nascer», Jus Navigandi, núm. 60 (2002), disponible en bttp://www1.jus.com.br/doutrinal texto.asp? $i d=3544$. Traducción: «El modelo español [...] permite la inseminación posterior a [sic] muerte del donador, desde que hecha dentro del plazo de seis meses a contar del fallecimiento del mismo y si consentida en escritura pública, salvaguardando del hijo todos los derechos que surgen de su filiación».

31 Resolução núm. 1.358, de 11 de noviembre de 1992.

${ }^{32}$ H. H. BARBOZA, A filiação em face da inseminação artificial e da fertilização «in vitro», Rio de Janeiro, Renovar, 1993. Traducción: «No [...] parece razonable considerar el embrión antes de la transferencia para el útero materno un nascituro».

33 P. L. NetTo LÔBo, op. cit., p. 52. Traducción: «El proyecto de Ley núm. 90 de 1990, del Senado Federal, que dispone sobre la reproducción asistida, establece que no se aplica a los embriones originados in vitro, antes de la introducción en el aparato reproductor de la mujer receptora, los derechos asegurados al feto». 
Cuando los plazos fijados en el art. 1.597 del Código Civil Brasileño vigentes para la presunción de la filiación fueran extrapolados, no se ve otra alternativa para el reconocimiento de filiación, sino la acción de investigación de paternidad ${ }^{34}$.

Como se puede observar, la ley brasileña es deficiente en la reglamentación de la filiación en los casos de inseminación artificial y fertilización in vitro homóloga post mortem, cuando considerado el casamiento. Igualmente, mayor insuficiencia disciplinar se constata cuando se cuida de unión estable, sobre todo porque dejó de mencionar ese tipo de entidad familiar cuando trata de presunción de filiación.

De hecho, los incisos II, IV y V del art. 1.597 del Código Civil Brasileño de 2002 no solucionan los casos en que la reproducción asistida ocurre entre compañeros. Así, socorrería al hijo concebido por inseminación artificial o fertilización in vitro homólogas póstumas apenas la vía judicial, o sea, la utilización de la acción de investigación de paternidad, lo que sería una discriminación para los hijos generados en la constancia de unión estable. A pesar de que se entiende el art. 1.597 del actual Código Civil debe ser aplicado integralmente también a los casos de unión estable y no apenas al matrimonio.

La orden jurídica francesa posee un dispositivo legal (Código de la Salud Pública, art. 152-2) que exige a la pareja de compañeros la comprobación de la vida en común por, lo mínimo, dos años, bien como la manifestación, previamente a la concepción del consentimiento de ambos ${ }^{35}$. Al contrario de Francia, Brasil no mantiene disciplina legal en este sentido.

Aunque alejada la cuestión de casamiento y de unión estable, todavía así la inseminación artificial y la fertilización in vitro homologas post mortem enfrentan una serie de resistencias.

Según Fabio Alves Ferreira, los argumentos contrarios a tal práctica reproductiva, cuando posterior a la muerte del padre, residen en el derecho de la familia y no del derecho a la identidad personal del hijo que, entonces ya nacería huérfano, no beneficiándose consciente y deliberadamente de la estructura familiar biparental, no olvidándose también de la distinta creada en lo que condiciona al establecimiento de filiación y del derecho sucesorio $^{36}$. Se añade aun dos aspectos que pueden ser utilizados como argumentos contrarios a la reproducción homóloga póstuma, caso no sean respetados: la dignidad de la persona humana y la paternidad responsable.

\footnotetext{
${ }^{34}$ A. Rizzardo, Direito de família..., op. cit., p. 525.

35 G. Calmon Nogueira da Gama, A nova filiação..., op. cit., p. 725.

${ }^{36}$ F. Alves FerReIrA, «Vivendo sem respirar...», op. cit.
} 
Existen algunos proyectos de ley en la Cámara de Diputados ${ }^{37}$ y del Senado Federal ${ }^{38}$ que tratan de la reproducción asistida. Sin embargo, de aquellos cuyo integro contenido se encuentran disponibles en la internet, se enfatiza que ninguno trata específicamente de la cuestión de filiación en los casos de inseminación artificial y fertilización in vitro homóloga post mortem. Se nota, por lo tanto, que todavía no existen manifestaciones legislativas destinadas a la resolución de las problemáticas pertinentes a la inseminación artificial y a la fertilización in vitro homólogas póstumas.

\section{EL DERECHO SUCESORIO DE LOS HIJOS GENERADOS POR INSEMINACIÓN ARTIFICIAL Y FECUNDACIÓN IN VITRO HOMÓLOGAS POST MORTEM}

\section{Consideraciones sobre la sucesión en general}

Suceder nada más es, pues, de lo que substituir tomar el lugar de otro individuo en el campo de los fenómenos jurídicos. En la sucesión, por lo tanto, hay una substitución del titular de un derecho, siendo este el concepto amplio de la sucesión en el Derecho ${ }^{39}$.

Según el art. 1.786 del Código Civil Brasileño vigente que «A sucessão dá-se por lei ou por disposição de última vontade» ${ }^{40}$, o sea, sucesión legítima o testamentaria. Y, de acuerdo con el art. 1.784, la herencia se transmite a los herederos legítimos y testamentarios cuando da abertura de la sucesión, esto es, en el exacto momento de la muerte del individuo, teniendo en cuenta la adopción del principio de saisine.

Pero ni todos los herederos reciben la herencia necesariamente. Advierte Heloisa Helena Barboza que existen tres condiciones para que un sucesor pueda recibir la herencia, sean ellas, «... ser vivo, ser capaz e ser digno» ${ }^{41}$ en el momento de la muerte del de cujus.

El Código Civil Brasileño de 2002 abordó la primera condición en su art. 2. ${ }^{\circ}$ al prescribir que «A personalidade civil da pessoa começa do nas-

${ }^{37}$ CÂmara dos Deputados, s.f., disponible en http://www.camara.gov.br.

38 Senado Federal, s.f., disponible en http://www.senado.gov.br.

39 D. Gozzo y S. De Salvo Venosa, «Do direito das sucessões: arts. 1.784 a 1.911», en A. Alvim y T. Alvim (coords.), Comentários ao Código Civil brasileiro, Rio de Janeiro, Forense, 2004, p. 3.

40 S. De Salvo Venosa (org.), Novo Código Civil..., op. cit., p. 453. Traducción: «La sucesión se otorga por ley o por disposición de la última voluntad».

${ }^{41}$ H. H. BARBOZA, A filiação em face..., op. cit., p. 54. Traducción: «Estar vivo, ser capaz y ser digno». 
cimento com vida; mas a lei põe a salvo, desde a concepção, os direitos do nascituro» ${ }^{42}$.

La capacidad de heredar es segunda condición. Silvio de Salvo Venosa acentúa que la regla general es que todos son capaces, siendo que apenas determinadas personas no tienen capacidad para recibir en ciertas herencias ${ }^{43}$.

Tratándose, pues, de vocación hereditaria, la primera constatación que debe ser hecha es aquella dispuesta en el ya transcrito art. 1.798 del Código Civil, o sea, el sucesor debe de haber nacido o ya concebido en el momento de la muerte del de cujus, sin embargo, el art. 1.799 señala algunas situaciones peculiares en el caso de sucesión testamentaria, dentro de las cuales está la posibilidad de ser llamado a suceder el hijo aún no concebido.

La legitimación para heredar puede ser de los convocados por testamento y/o en función de la vocación hereditaria. Igualmente, existe una orden de llamado de sucesores, esto es, una orden de vocación hereditaria indicada en el art. 1.829 del Código Civil Brasileño vigente proporciona en su art. 1.814 las hipótesis de indignidad que aleja al heredero de la sucesión.

\section{Disciplina legal dada en Brasil acerca de la sucesión: problemática y reflexiones específicas en los casos de inseminación artificial y fertilización in vitro homólogas post mortem}

Si , en el momento de la muerte del de cujus, el su descendientes - heredero necesario- estuviera vivo, fuera capaz y digno, será el primero a ser llamado a recibir la herencia, por fuerza de vocación hereditaria prevista en el art. 1.829 del Código Civil Brasileño, no ignorando eventual situación de competencia o no con el cónyuge o compañero. Así, el hijo será contemplado con la herencia del padre fallecido, no siendo relevante se generado mediante reproducción natural o médicamente asistida. Los problemas, sin embargo, se inician cuando los gametos del de cujus o los embriones formados con su material genético estuvieran congelados en el momento de su muerte.

${ }^{42}$ S. De Salvo Venosa (org.), Novo Código Civil..., op. cit., p. 35. Traducción: «La personalidad civil de la persona comienza del nacimiento con la vida, pero la ley pone a salvo, desde la concepción, los derechos del feto».

43 S. De Salvo Venosa, Direito civil: Direito das sucessões, São Paulo, Atlas, 2004, p. 77. 
En el caso de los hijos que poseen la paternidad presunta por fuerza de los incisos I e II del art. 1.597 del Código Civil Brasileño de 2002, no se vislumbra tantas problemáticas. De manera diferente ocurre con aquellos que no se encuadran exactamente en las hipótesis de presunción del aludido dispositivo legal.

La gran polémica en el caso de la inseminación artificial y de la fertilización in vitro homólogas post mortem reside justamente en el hecho del hijo, todavía no haber nacido en el momento de la muerte del de cujus y, como mencionado, estar vivo es una de las condiciones para el sucesor heredar. Por otro lado, el art. $2^{\circ}$ del actual Código Civil proporciona que «[...] a lei põe a salvo, desde a concepção, os direitos do nascituro». ${ }^{44}$ Así se deriva que el embrión es feto porque ya hubo la concepción. Sin embargo, las problemáticas sucesorias siguen sin resolverse, pues existe la cuestión e aquel que ni siquiera estaba concebido al fallecimiento del hombre, también llamado nondum conceptus ${ }^{45}$.

En la inseminación artificial homóloga post mortem no hay concepción en el tiempo del óbito del hombre, ya que apenas existen espermatozoides y óvulos crio preservados. Ya en la fertilización in vitro homóloga póstuma pueden ocurrir dos situación: a) la clínica utiliza dos espermatozoides congelados del entonces fallecido y, con los óvulos de la mujer, efectúa la fecundación (en el momento de óbito del hombre apenas hay gametos; la concepción ocurre solamente después de óbito); b) la clínica posee los embriones ya crio preservados, ya que la colecta de las células germinativas e la fecundación ocurrió antes de la muerte del hombre.

El inciso III del art. 1.597 del Código Civil Brasileño de 2002 no fija un límite temporal para que ocurra la concepción y, entonces ya se ve la problemática de una espera por tiempo indefinido de eventual utilización del material genético crio conservado del fallecido.

Hay todavía la situación de aquel que todavía no es concebido, o sea, cuando ni siquiera existe embrión.

El no concebido puede ser beneficiado con la herencia del, de cujus, a través del testamento, por fuerza del inciso I del art. 1.799 del Código Civil Brasileño. No obstante, fue fijado el límite temporal de dos años de abertura de la sucesión para que ocurra la concepción (párrafo $4^{\circ}$ del art. 1.800), a fin de evitar la espera ad eternum.

${ }^{44}$ S. De Salvo Venosa (org.), Novo Código Civil..., op. cit., p. 35. Traducción: «La ley pone a salvo, desde la concepción, los derechos del feto».

45 D. Gozzo y S. De Salvo Venosa, «Do direito das sucessões...», op. cit., p. 80. 
José Luiz Gavião de Almeida reflexiona que mejor sería que fuese establecido un plazo para el nacimiento del contemplado y no para su concepción, pues como está la ley, podrá ser necesaria una investigación acerca de la edad de gestación en virtud de esta ni siempre ser exacta ${ }^{46}$.

La disciplina legal también es deficiente porque en el inciso I del art. 1.799 del Código Civil vigente se constata que están mencionados los hijos de personas indicadas por el testador, sugiriendo cuidarse de la prole de terceros, o sea, sin pormenorizar la posibilidad del testador indicar sus propios hijos, aunque que no concebidos en el momento de la muerte.

Si mismo con la sucesión testamentaria ya existen factores de complicación, ¿cómo se resolvería, la situación del hijo concebido por inseminación artificial o fertilización in vitro homólogas post mortem cuando inexistente testamento, o sea, en la sucesión legítima?

Siendo establecida la presunción de la filiación, el hijo heredará de su fallecido padre. Se pregunta, por lo tanto, cual direccionamiento a ser dado cuando no existe tal presunción legal.

La doctrina brasileña se divide.

Algunos autores tales Eduardo de Oliveira Leite ${ }^{47}$, Tycho Brahe Fernandes ${ }^{48}$, Heloisa Helena Barboza ${ }^{49}$ e Guilherme Calmon Nogueira da Gama ${ }^{50}$ entienden que este hijo no hereda en la sucesión legítima, pero solamente en la testamentaria caso existiese disposición del de cujus en este sentido. Especialmente aspectos prácticos son tomados en cuenta para la negociación del derecho sucesorio de los hijos concebidos por inseminación artificial o fertilización in vitro homólogas póstumas, a ejemplo de espera interminable del nacimiento y la división de la herencia en tantas partes como fuera los herederos mas la cantidad de embriones crio preservados. José de Oliveira Ascensão, igualmente entiende que el hijo póstumo no puede ser legitimado a suceder porque sería prácticamente imposible establecer el mapa de los herederos y el esclarecimiento de las situaciones sucesorias, bien como la repartición hecha estaría sujeta a ser alterada indefinidamente ${ }^{51}$.

${ }^{46}$ J. L. Gavião DE AlmeIDA, «Direito das sucessões, sucessão em geral, sucessão legítima: arts. 1.784 a 1.856», en A. VillaçA Azevedo (coord.), Código Civil comentado, op. cit., p. 111.

${ }^{47}$ E. De Oliveira Leite, «Direito das sucessões: arts. 1.784 a 2.027», en S. De FigueiRedo Teixeira, Comentários ao novo Código Civil, Rio de Janeiro, Forense, 2003, p. 105.

48 T. BRAHE Fernandes, A reprodução assistida..., op. cit., p. 119.

${ }^{49}$ H. H. Barboza, $A$ filiação em face..., op. cit., p. 55.

50 G. Calmon Nogueira da Gama, A nova filiação..., op. cit., p. 733.

${ }^{51}$ J. De Oliveira Ascensão apud C. M. Da Silva Pereira, Instituições de Direito civil: 
Ocurre que esto sería un factor de discriminación, ya que los hijos naturales, adoptados, concebidos de inseminación heteróloga y de fertilización in vitro tienen derecho a la sucesión, independiente de la disposición testamentaria.

La ausencia de solución legislativa al respecto importa, sin dudas, en una gran inseguridad jurídica. En esta oportunidad, Silvio de salvo Venosa recomienda que la materia referente a reproducción asistida en general sea reglamentada en ley especifica delante de la insuficiente y precaria disciplina dada en el Código Civil Brasileño de $2002^{52}$.

En efecto, la inestabilidad social en los casos comprendidos en la temática de esta pesquisa es algo que debe ser repudiado. Sin la existencia de una disciplina legal, clara y firme al respecto, la reproducción asistida homóloga post mortem puede ser practicada para fines diversos de aquellos para el cual realmente importa la generación de un hijo.

Guilherme Calmon Nogueira da Gama, considerando la prohibición de esta práctica en Brasil, apunta una forma de hijo así pudiendo ser indemnizado por el hecho de no ser beneficiado en la sucesión de cujus: el hijo puede pleitear la reparación de los daños materiales que sufrir de su madre y de los profesionales que la auxiliaron a procrear utilizando el semen del cónyuge o compañero ya fallecido, con fundamento en la responsabilidad civil ${ }^{53}$. Ya el autor Luis Manuel Moreira de Almeida lucha por una solución intermediaria, en vez de prohibir o liberar totalmente la reproducción asistida póstuma: permitir la inseminación post mortem por motivos graves o ponderosos con los consiguientes derechos de filiación y sucesión de su padre ${ }^{54}$.

Hecho es que la insuficiencia de la disciplina legal perjudica a quien más necesita de protección: el nuevo ser humano generado. El principio de dignidad de la persona humana debe ser tomado en cuenta para garantizar sus derechos. Entiéndase inaceptable el mero argumento de que, por haber sido concebido con material genético de su fallecido padre después de la muerte de él, el hijo queda fuera de los derechos que tendría en el caso que fuese concebido conforme a la hipótesis de presunción legal de filiación (art. 1.597 del Código Civil Brasileño de 2002) o aun si beneficia-

\footnotetext{
Direito das sucessões, 15. . ed., Rio de Janeiro, Forense, 2004, p. 33.

52 S. De Salvo Venosa (org.), Novo Código Civil..., op. cit., p. 287.

53 G. Calmon Nogueira da Gama, A nova filiação..., op. cit., p. 733.

54 L. M. Moreira DE AlmeIDA, «A medicina moderna da procriação no Direito de família e de sucessões», Associação portuguesa de notários, 2005, disponible en bttp://www.geocities.com/apn_notarios/BERLIM1.btm.
} 
da fuese por la sucesión testamentaria (art. 1.799 del Código Civil Brasileño de 2002). Al final si fue suprimida la discriminación entre hijos, todos deben tener iguales derechos, sobretodo porque el hijo no tiene cualquier culpa de haber sido concebido mediante inseminación artificial o fertilización in vitro homólogas post mortem.

Definitivamente, el Código Civil Brasileño de 2002 no consiguió éxito en abordar lo suficiente la cuestión de los derechos hereditarios de los hijos concebidos por inseminación artificial o fertilización in vitro homologas post mortem. Las problemáticas ya se inician en la determinación de la filiación de estos hijos y prosigue en la diferencia hecha entre aquellos hijos que no se enmarcan en el rol de las presunciones de paternidad y también no fueron beneficiados por disposiciones testamentarias.

Esta vez, se entiende que, si no fuese prohibida expresamente la utilización de técnicas de reproducción asistida homólogas póstumas, se hace necesario la preservación de los derechos del hijo así proveniente, bajo pena de incurrir en no respetar el principio de igualdad entre los hijos y de la dignidad de la persona humana. No obstante, de otro lado se tiene la cuestión de seguridad jurídica. Esa cuestión puede ser resuelta y/o controlada mediante el establecimiento de plazos para la aplicación de la reproducción médicamente asistida, protegiendo a los demás herederos del de cujus y de eventuales terceros de buena fe, además de sanciones para aquellos que no observaron tales plazos. Así se estaría dificultando los derechos sucesorios del hijo generado por inseminación artificial o fertilización in vitro homólogas post mortem en cualquier caso.

De modo general, se concluye que el hijo concebido por inseminación artificial o fertilización in vitro homólogas post mortem tiene el derecho a su filiación reconocida, bien como de haber asegurado sus derechos de herencia, bajo pena si violar el principio constitucional de no discriminación entre los hijos. Las cautelas básicas que el legislador debería haber señalizado podrían ser relativas a la igualdad de condiciones en el caso del casamiento y de unión estable, la determinación de un plazo para la realización de la reproducción asistida póstuma, la exigencia de previo y expreso consentimiento del marido o compañero y el establecimiento de sanciones para la progenitora, el médico y la clínica que realizaron la procreación médicamente asistida sin la observación de estas determinaciones. Tales cautelas no desampararían al hijo y contribuirían de sobremanera para la situación de los derechos sucesorios, no olvidándose de la seguridad jurídica. 
La reglamentación firme y específica de la materia, sea como la inserción de nuevos dispositivos legales en el Código Civil Brasileño de 2002, sea a través de la legislación especial, es medida que se impone.

Las cuestiones de filiación y de derecho sucesorio de los hijos provenientes de inseminación artificial o fertilización in vitro homólogas póstumas no son temas apenas para mera discusión, pero así, a ser efectivas delante de la realidad actual vivida y futura, en que muchas otras cuestiones podrán surgir delante del intenso avance médico y biotecnológico, especialmente en el área de reproducción asistida.

Así se entiende que negar esta realidad y la necesidad de la disciplina al respecto de la filiación y del derecho hereditario de aquellos provenientes de inseminación artificial o fertilización in vitro homólogas póstumas equivaldría al abandono de la búsqueda y de la efectividad de la justicia, alcance constante que el estado debe priorizar por bien común de la sociedad. 